\title{
Optimized Production of Syngas from Rice Hush Using Steam Explosion in Dual Fluidized Bed Gasifier
}

\author{
Ahmad F'*, Ahmad N², Asghar U', Ali $A^{1}$ and \\ Masoom A $^{1}$ \\ ${ }^{1}$ Department of Chemical Engineering, University of \\ WAH, WAH Engineering College, Pakistan \\ ${ }^{2}$ Department of Microbiology, PMAS Arid University, \\ Pakistan \\ *Corresponding author: Fazeel Ahmad, Department \\ of Chemical Engineering, University of WAH, WAH \\ Engineering College, Pakistan
}

Received: March 04, 2021; Accepted: March 24, 2021; Published: March 31, 2021
Abstract
Converting rice husk into energy is a promising method of generating enewable energy and reducing greenhouse gas emissions. In this research rice hush is considered as biomass fuel. The characteristics of rice husk gasification were investigated at an Equivalence Ratio (ER) of $0.25-0.38$ and a gasifier temperature of $750-870^{\circ} \mathrm{C}$ in 20 tons per day (TPD) using steam explosion process in fluidized bed gasifier system. Different operation conditions, temperatures and loads, are investigated for their effects on the compositions, calorific properties, gasification efficiencies of syngas. The effects of the critical parameters, namely, Steam-to-Biomass Ratio (S/B), Particle size variation and gasification temperature on the quality of the product gas as well as the gasifier cold gas efficiency were analyzed. This is the new finding in the research. The optimal conditions of the gasification operation were an ER of 0.20 and gasifier temperature of $800^{\circ} \mathrm{C}$. The low heating value of the gas product and cold gas efficiency were $1390 \mathrm{kcal} / \mathrm{Nm}^{3}$ and $75 \%$, respectively. After passing the generated gas through the gas cleaning units, it was confirmed that the tar in the product gas was removed with an efficiency of $98 \%$. The cleaned product gas was used for the operation of $420 \mathrm{~kW}$, gas engine. Pressure loss often occurred at the bottom of the gasifier during the gasification operation; we found that the agglomerates generated by the gasification process caused it. To prevent the pressure loss caused by the agglomerates, the stable control of temperature inside the gasifier is needed and an ash removal device remove agglomerates should be installed to maintain stable long-term operation. This paper leads towards the production of Syngas and further on the electricity from the rice husk, an eminent biomass, copiously available all around the world. Especially in Pakistan, the rice is used abundantly so the raw material is easily available. The gas is produced using the gasification process in dual fluidized gasifier. It is a wonderful alternative to the natural gas with high calorific value. The sulfur contents are quite less compared to natural gas. It also have a good correlation with environment as flue gases emission is negligible relative to other source like coal, wood, plastic, waste etc. Another benefit of this process is the waste management and pollution control. The results are developed by using the detailed analysis of the process values of plants which is generating electricity by rice husk gasification. We learned, all results revealed that the dual fluidized bed gasification is more economical and efficient method compared to all other methods for commercial scale production of syngas. Results are analyzed which imply that the biomass is more gigantic source which replace the fossil fuels and leads towards the green energy in a more economical way. This paper provides an overview of previous works on combustion and gasification of rice husk in atmospheric fluiuidized bed reactors and summarizes the state of the art knowledge. As the high ash content, low bulk density, $\mathrm{p}$ characteristics and low ash melting point makes the other types of reactors like grate furnaces and downdraft gasifers either inefficient or unsuitable for rice husk conversion to energy, the fluiuidized bed reactor seems to be the promising choice. The overview shows that the reported results are from only small bench or lab scale units. Although a combustion efficiency of about $80 \%$ can normally be attained; the reported values in the literature, which are more than $95 \%$, seem to be in higher order. Combustion intensity of about $530 \mathrm{~kg} / \mathrm{h} / \mathrm{m}^{2}$ is reported. It is also technically feasible to gasify rice husk in a fluidized bed reactor to yield combustible producer gas, even with sufficient heating value for application in internal combustion engines.

Keywords: Rice Hush; Dual fluidized bed gasifier; Syngas Production; Combustion; Gasification; Optimization 


\section{Introduction}

The world is moving towards energy crisis due to continuous deployment of natural sources. It is the need of the hour to invent alternative and sustainable sources for energy production. Biomass is more flourishing, extended and sustainable source to produce energy and other chemical products. Keeping scarcity and environmental hazards of fossil fuels in mind, researchers are increasingly shifting their attention to renewable energy sources. Biomass is considered as one of the most favored forms of renewable sources [1]. Apparent carbon neutrality and worldwide availability are the most notable characteristic of biomass [2,3]. Major types of biomass are primary biomass, collected directly from plantation areas and waste biomass like municipal solid wastes.

Energy crops are mainly grown for use in energy conversion systems. In both large and small scale power generation, biomass can be utilized as a replacement of fossil fuels [4-6]. Biomass gasification is a process where biomass undergoes thermal conversion to produce a combustible gas mixture, which contains hydrogen, methane, carbon monoxide, carbon dioxide, and water vapor. In air gasification, solid biomass is combusted partially in the presence of air at substoichiometric ratio and the product gas contains substantial amount of $\mathrm{N}_{2}$. In steam gasification, steam is the primary gasifying agent and the product gas is rich in $\mathrm{H}_{2}$ while $\mathrm{N}_{2}$ content is minimal. Further, steam gasification produces minimal amounts of oxides of Sulphur and Nitrogen because of the oxygen-deficient condition and lower gasification temperature [7]. There are different gasifiers available in the market. Of them, Fluidized Bed Gasifiers (CFBs) are suitable for the gasification of agricultural residues such as rice husk, straw, stalk etc. utilizing steam as gasification agent. The parameters that affect the performance of gasification are the gasifying agent (air or steam), gasification temperature and the size of the biomass particle $[8,9]$.

Higher gasification temperature and small particle size are favorable for the gasification process, as they help to increase in conversion of biomass while reducing the concentration of char. Advanced Simulation and Process Engineering (ASPEN) can be used to model gasification processes and to estimate the composition of syngas obtained after gasification. Li et al. [10] developed a novel trigeneration system taking biomass and solar energy as co-feeds, and they performed energy analysis on the system. The effects of Steam-toBiomass Ratio (S/B) and equivalence ratio were investigated, and the highest destruction of exergy was found to be in the gasifier. Zhang et al. [11] modeled a biomass partial gasification process. The authors carried out the exergy and energy analyses of the gasification model. The performance of gasification model was investigated considering different parameters of the system and exponential increase in the product of exergy destruction and time was observed after carbon conversion ratio value of 0.7 . Chen et al. [12] modeled a supercritical water coal gasification system and $\mathrm{O}_{2}-\mathrm{H}_{2} \mathrm{O}$ coal gasification system, and reported the comparative performances (Figure 1).

In Pakistan, primary energy sources are mainly thermal (87\%), hydropower (11\%) and nuclear power (1.7\%). The total energy supply in 2013 was 64.5 Million Tons of Oil Equivalents (MTOE). The primary energy sources were Oil (20.96 MTOE), Gas (31.1 MTOE), LPG (0.3 MTOE), Coal (3.8 MTOE), Hydroelectricity (7.1 MTOE), Nuclear electricity (1 MTOE) and imported energy (0.08 MTOE)

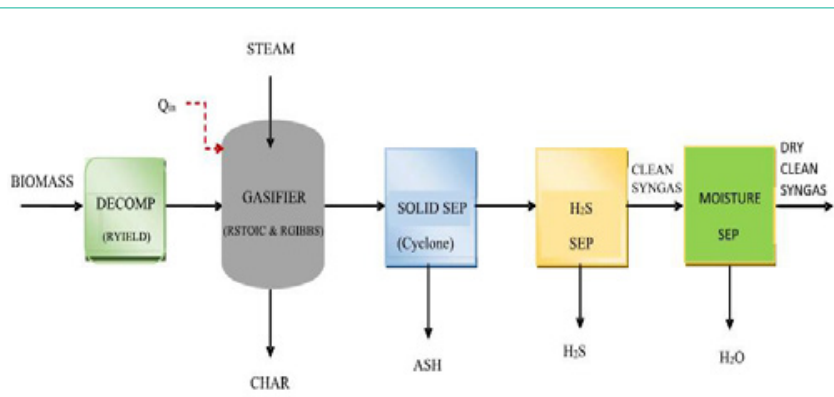

Figure 1: Gasification of Biomass [2,3].

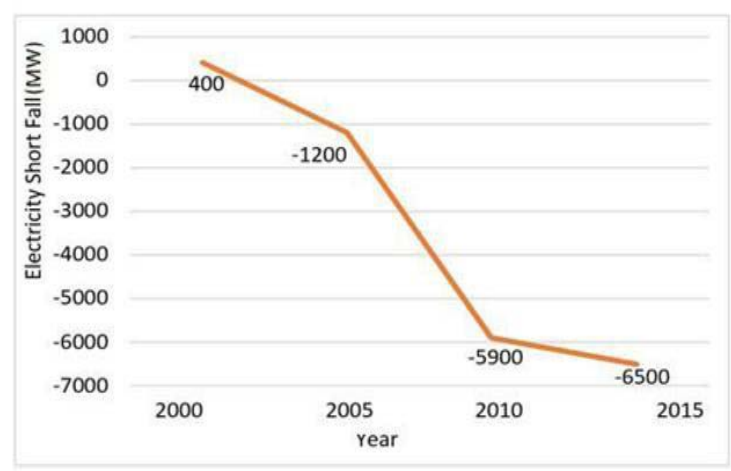

Figure 2: Difference between power supply and demand in Pakistan Source [5]

with different level of share. The share of gas was $48.2 \%$ in total energy mix of country, followed by oil $32.5 \%$, $\%$, hydro $11 \%$, coal 6 , nuclear $1.7 \%$, Liquid Pressurized Gas (LPG) $0.5 \%$, and imported energy $0.1 \%$. In 2013 , industrial sector was the largest energy consumer, which accounted $35.5 \%$ of the total 40.18 million TOE energy consumption, followed by transportation sector of $31.6 \%$. Domestic sector was the largest consumer of electricity, accounting for $47 \%$ of the total 76789 GWh electricity consumption, followed by industrial sector with $29.05 \%$ [6]. Pakistan electricity generation capacity at the time of independence was only $10.7 \mathrm{MW}$, which increased significantly from $7000 \mathrm{MW}$ in 1980 to about $16000 \mathrm{MW}$ in 2013-14, but this supply amount is still much less than the rising demand. Currently, Pakistan is facing serious electricity shortfall, about 6-8 hours in urban areas and 8-10 hours in rural areas in 2012. The electricity gap between supply and demand is depicted in Figure 2.

\section{Rice Production in Pakistan}

Rice in Pakistan is a monsoon crop but the introduction of hybrid varieties in recent years has influenced the timing of sowing and transplanting. Hybrid varieties are sown as early as March and April instead of June and July. However, sowing timing is heavily influenced by the extent and spread of monsoon rains, and the availability of underground and irrigated water. Irrigation water is mostly sourced from the run off of the Himalayan glacier melt into the Indus river basin, so temperatures during the months of May and June are critical in determining the season's water availability. The growing areas of rice in Pakistan are given below. The Table 1 shows different zone of rice production in the Pakistan (Figure 3 and Table 1). 
Table 1: Zones of Rice Production [13,14].

Zorthern high mountainous areas of Khyber Pakhtunkhwa (Swat and Kagan) with sub-humid climate, average rainfall of 750-1000 mm. Lies between the Zone I Ravi and Chenab rivers in the central Punjab.

Zone $\|$ This is the famous premium zone and Basmati rice is exclusively produced in this zone along the Kalar tract consisting of Sailkot, Sheikhupura, Narowal, Gujranwala, Hafizabad and Lahore districts.

Zone III High temperature and sub-tropical climate with average rainfall of $100 \mathrm{~mm}$ make it best suited for long grain rice.

Zone IV Indus delta basin in Lower Sindh (Badin and Thatta Districts). Its climate is arid tropical and is suited for coarse varieties.

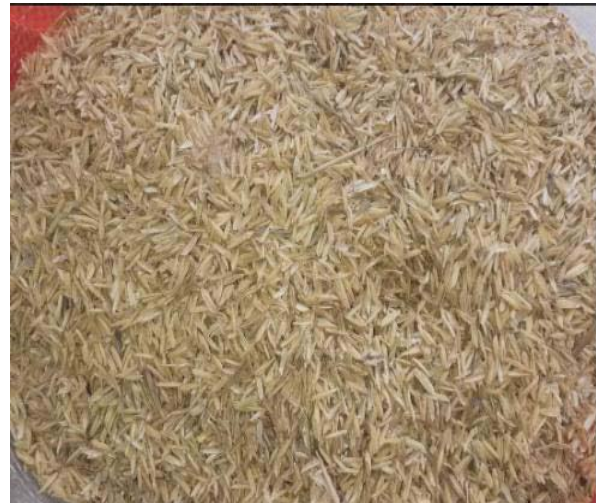

Figure 3: Rice husk feedstocks.

\section{Consumption}

MY 2019/2020 consumption is forecast at 2.9 million tons at par with the current marketing year. Unlike many other Asian countries, rice is not considered a staple food crop in Pakistan. Traditionally, 40 to 45 percent of the crop is used for local consumption, with the balance exported. Pakistanis, in general, prefer the higher priced Basmati rice if they can afford it, if not they consume long grain IRRI rice, but wheat is the favored staple. In 2016, domestic rice prices displayed an upward trend and the price of rice in December 2016 was nine percent higher than in December 2015. According to trade sources an estimated 200,000 tons of 40-100 percent broken rice is used in poultry and animal feed annually.

\section{Trade}

Pakistan has so far exported 1.22 million metric tons as compared to 1.72 million metric tons during the same period a year ago. MY 2016/17 rice exports are projected at 4.0. Million metric tons down seven percent from the last year's figure of 4.3 million metric tons. Pakistan's rice exports are facing stiff competition from Vietnam and Thailand. Currently the exporters from these countries range of $\$ 355$ 360 per ton for $5 \%$ broken rice, while prices for Pakistani rice in the same category is hovering around \$380 FOB Karachi. Pakistan's rice exports given below. The domestic market is protected from imports by a 10 percent tariff and strong preferences for domestic rice.

\section{Gasification}

Gasification is basically a technological process that involves the conversion of carbonaceous (carbon based) raw material into synthesis gas using heat, steam \& pressure. This process involves the reaction of carbonaceous feedstock with an oxygen containing reagent which may either be oxygen, air, steam or carbon dioxide, generally at temperatures in excess of $800^{\circ} \mathrm{C}$. This process takes into account the partial oxidation of substance which means that amount of oxygen is supplied in a limited way such that the fuel is not completely oxidized and it causes combustion to not occur completely. Although the process is largely exothermic, however, some heat is still required to initiate the gasification process \& to sustain it for effective operation. The demand of gasification systems is also increasing because they are used to turn feed stocks like coal into useful chemical products like ammonia. The main product is a synthesis gas (syngas), which contains: Carbon monoxide, Hydrogen Methane. Typically, the gas generated from gasification will have a net calorific value of $4-10 \mathrm{MJ} / \mathrm{Nm}^{3}$. The other main product produced by gasification is a solid residue of non-combustible materials (ash) which contains a relatively low level of carbon.

\section{History of gasification}

The gasification process is one of the oldest methods in which heat and light has been produced in the old times and with the passage of time the process for gasification has gotten more attention. Now, in the current time the biomass gasification is the challenging one which can produce huge amount of syngas. Table 2 shows the syngas production in which different production methods have been discussed all over the world from the start of process to the end of process in which synthetic fuel to green gas emission gas has been produced.

\section{Process in gasification}

A chemical reaction known as the water gas shift reaction helps to balance the carbon monoxide, steam, carbon dioxide and hydrogen in the gasifier establishing a chemical equilibrium during the final step of the process. The different process of gasification has been shown in the Figure 4.

\section{Chemistry of gasification}

During the process of gasification of solid carbon whether in the form of coal, coke, char or biomass, the principal chemical reactions

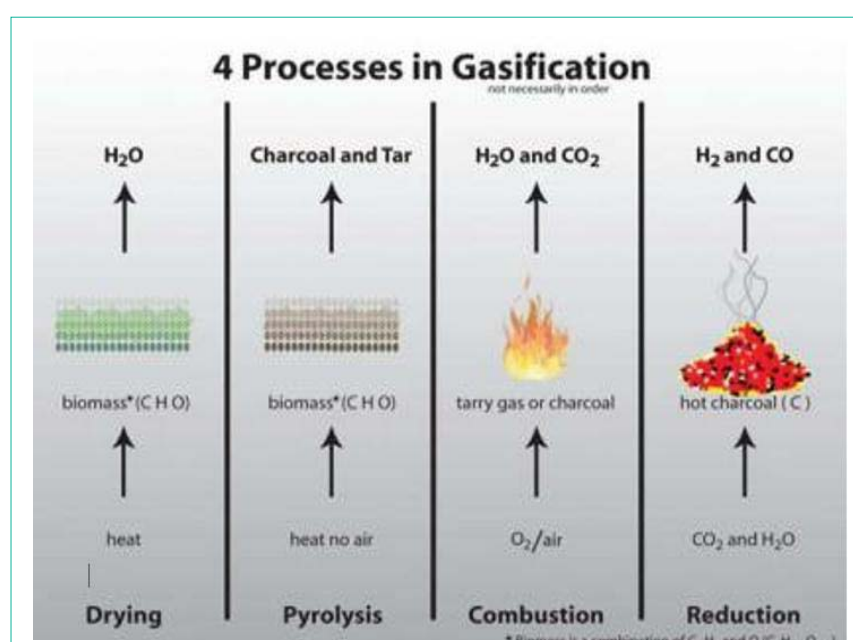

Figure 4: Processes in Gasification [6,7]. 


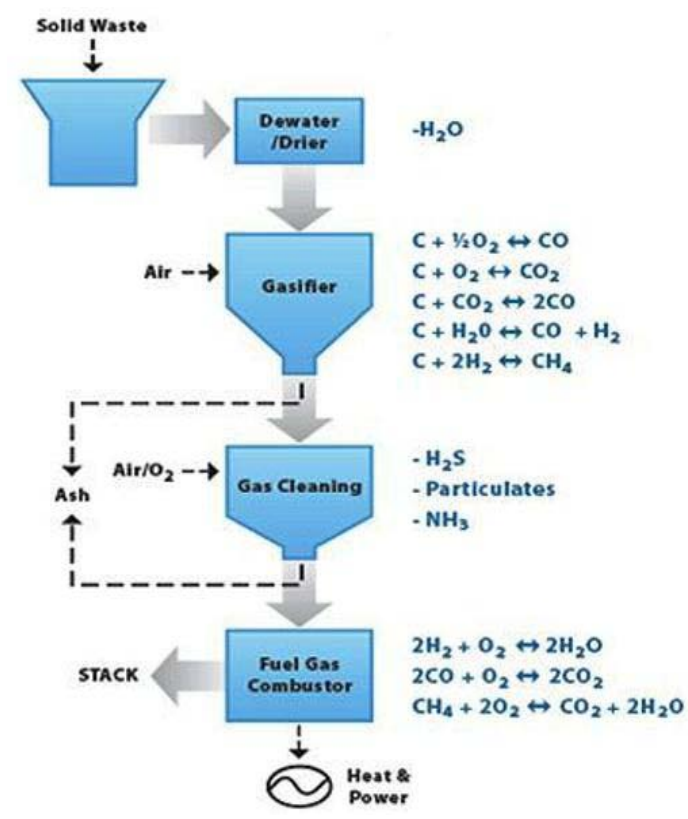

Figure 5: Syngas Production form Biomass [7,8].

are those that involve formation of carbon, carbon monoxide and carbon dioxide, hydrogen, steam and methane.

\section{Fluidized bed gasifier reactions}

Fluidized bed gasifiers are typically operated in the range of 800 $1000^{\circ} \mathrm{C}$ to avoid ash agglomeration, which is satisfactory for biomass utilization. Unlike other reactor types, a fluidized bed gasifier contains a bed of inert materials that serves as heat carrier and mixer, while the gasifying medium acts as the fluidizing gas. Typically, biomass particles are heated to bed temperature (as a result of contact with hot bed solids) and undergo rapid drying and pyrolysis, producing char and gases. The pyrolysis products break down into non-condensable gases after contact with hot solids (Figure 5).

\section{Materials and Methods}

Rice husk feedstock was gathered from local rice mill was ovendried at $83^{\circ} \mathrm{C}$ overnight before grinding. The proximate analysis, elemental analysis and LHV of rice husk are shown in after pulverizing and sieving, the particle diameter of rice husk is less than $200 \mathrm{~mm}$ [16-18]. The RH was sun-dried for a period of 35-49 h before it was pulverized to $250-1000 \mu \mathrm{m}$ different particle sizes. The characteristics of RH were presented in Table 1.

\section{Experimental Setup}

\section{Experimental procedure feasibility}

The proximate analysis, elemental analysis and LHV of rice husk. Rice husk was combined with oxygen carrier at a mechanical mixer for $30 \mathrm{~min}$ in order to ensure the uniformity of samples. And then they were placed in the center of quartz tube. Before experiment, $\mathrm{N}_{2}$ was ventilated into the quartz tube for $30 \mathrm{~min}$ at $90 \mathrm{ml} / \mathrm{min}$ in order to maintain the inert atmosphere. When the reactor is heated to the desired temperature, the quartz tube with oxygen carrier and rice husk is loaded into the reactor for 30min [19]. During the experiment, $\mathrm{N}_{2}$ was ventilated into the quartz tube at $100 \mathrm{ml} / \mathrm{min}$. After condensation,
Table 2: Syngas production methods [15]

\begin{tabular}{|c|l|}
\hline $1850-1940$ & $\begin{array}{l}\text { To produce-town gas for light \& heat. } \\
\text { Gasification of coal- All gas for fuel \& light. }\end{array}$ \\
\hline $1940-1975$ & $\begin{array}{l}\text { To produce synthetic fuel. } \\
\text { To produce liquid fuel \& chemicals. }\end{array}$ \\
\hline $1975-1990$ & $\begin{array}{l}\text { First Integrated Gasification Combined Cycle (IGCC) electric } \\
\text { power plant. }\end{array}$ \\
\hline $1990-2000$ & US Agencies provide financial support for IGCC process. \\
\hline $2010-$ Present & Turnkey thermal \& power Greenhouse gas from biomass. \\
\hline
\end{tabular}

Table 3: Proximate and Ultimate Analysis of Rice Hush.

\begin{tabular}{|c|c|c|c|}
\hline \multicolumn{2}{|c|}{ Proximate Analysis $^{\mathrm{c}^{*}}(\mathbf{W t} \%)$} & Ultimate Analysis $\left.^{\mathrm{d}^{*}} \mathbf{( W t} \%\right)$ & LHV (KJ/kg ) \\
\hline Moisture & 8.34 & $\mathrm{C}$ & 40.87 \\
\hline Ash & 12.13 & $\mathrm{H}$ & 5.45 \\
\hline Volatile & 64.33 & $\mathrm{O}$ & 52.51 \\
\hline Fixed carbon & 15.2 & $\mathrm{~N}$ & 0.83 \\
\hline \multicolumn{2}{|c|}{} & $\mathrm{S}$ & 0.34 \\
\hline
\end{tabular}

c*: On wet basis.

$\mathbf{d}^{*}$ : Dry basis.

Table 4: Design Array with input variables.

\begin{tabular}{|c|c|c|c|c|c|}
\hline \multirow{2}{*}{ Variable } & \multirow{2}{*}{ Unit } & \multicolumn{5}{|c|}{ Levels } \\
\cline { 4 - 6 } & & $\mathbf{1}$ & $\mathbf{2}$ & $\mathbf{3}$ & $\mathbf{4}$ \\
\hline Reaction temperature & ${ }^{\circ} \mathrm{C}$ & 650 & 750 & 850 & 910 \\
\hline Particle size of $\mathrm{RH}$ & $\mathbf{M m}$ & 245 & 500 & 755 & 980 \\
\hline Amount of catalyst & $\mathrm{wt} \%$ & 2.45 & 5 & 7.55 & 9.8 \\
\hline Air to Biomass ratio & --- & 0.96 & 1.24 & 1.55 & 1.74 \\
\hline
\end{tabular}

the flue gas was collected by gas collecting bag and then was measured by Gas Chromatograph (Table 3).

Ash Content (AC), Volatile Matter (VM) and Moisture Content (MC) were determined using the thermo gravimetric analyzer EXSTAR TGA/DTA 6300 (Seiko Instrument Inc., Japan). The weight percentage of the Fixed Carbon (FC) was calculated. Meanwhile, LECO CHNS-932 (LECO Corporation, USA) ultimate elemental analyzer was used to perform the ultimate analysis to understand the amount of elements $\mathrm{C}, \mathrm{H}, \mathrm{N}, \mathrm{O}$, and $\mathrm{S}$ in $\mathrm{RH}$. This is a carrying on study of previous literature in which the catalyst chosen was CBA $[20,21]$. The CBA was provided by a power plant owned by Tenaga Nasional Berhad (TNB) in Seri Manjung, Perak, Malaysia and it was sieved to $<50 \mu \mathrm{m}$ particle size to enhance the diffusion rate between reactant and catalysts.

\section{TGA-MS Setup}

The thermo gravimetric analyzer (EXSTAR TG/DTA 6300) was used to carry out the gasification process and the composition of gas produced was assessed with a mass spectrometer connected. The $\mathrm{RH}$ sample and CBA catalyst were added into a ceramic crucible and inserted into the TGA equipment under $\mathrm{N}_{2}$ environment according to the design array shown in Table 4.

The levels of the critical variables are determined based on the study by Shahbaz et al. (2017) [22]. A continuous flow of nitrogen gas of $100 \mathrm{ml} / \mathrm{min}$ was introduced and kept for $10 \mathrm{mins}$ at a temperature of $50^{\circ} \mathrm{C}$ to purge the pyrolysis zone, preventing unwanted sample oxidation. Then, the air supplied as a gasifying agent was introduced into the system at a flow rate of $100 \mathrm{ml} / \mathrm{min}$. All the samples were heated to the desired temperatures, as in Table 2, with $50^{\circ} \mathrm{C} / \mathrm{min}$ 


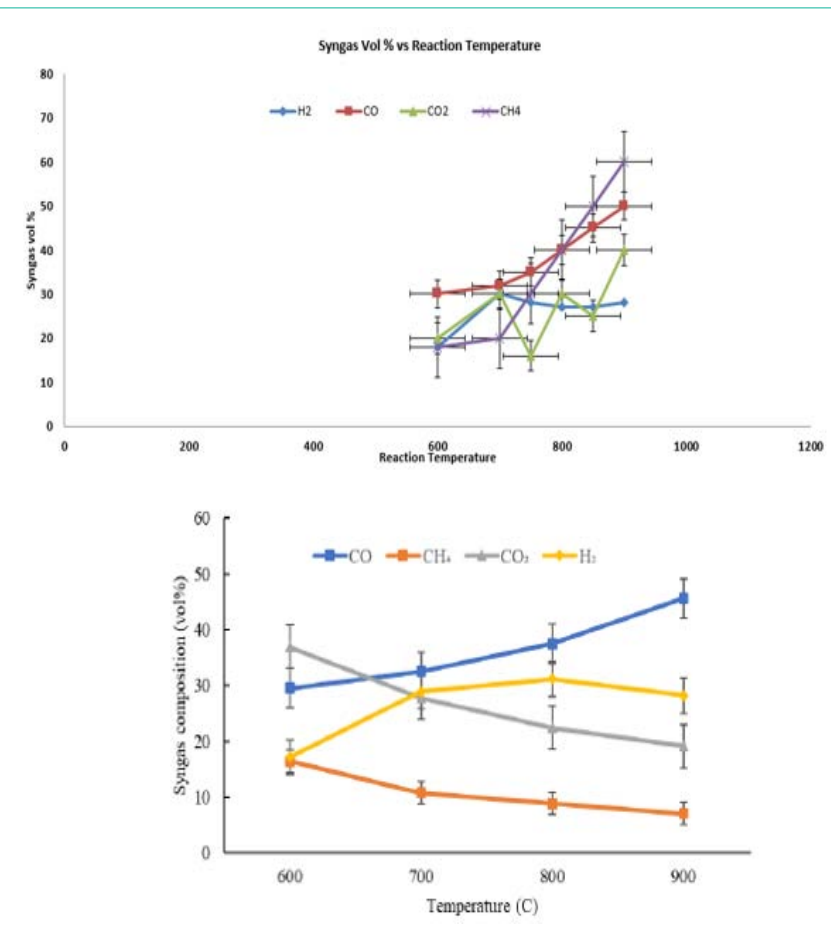

Figure 6: Effect of reaction temperature on gas composition [6].

heating rate and kept constant for 10mins to ensure the completion of the gasification process.

\section{Results and Discussion}

\section{Effect of reaction temperature on syngas production}

Figure 6 illustrates the results of effect of reaction temperature on the syngas composition. It is found that the $\mathrm{H}_{2}$ composition rises with temperature, from 17.0 to $28.0 \mathrm{vol} \%$. As predicted, the rising temperature lead to a higher gas yield, and a lesser tar and solid residues, which possibly caused by the further cracking of liquids and char with the gasifying medium. The rise in syngas composition from 68.2 to $74.8 \mathrm{vol} \%$ at temperature from 600 to $900{ }^{\circ} \mathrm{C}$ can be explained through several reasons [23].

\section{Effect of particle size distribution on syngas production}

Figure 7 illustrates the syngas composition performance for $\mathrm{RH}$ at various particle size as in Table 4 . It is found that the syngas production clearly increased with decreased particle size. This trend can be explained through mass transfer and diffusion study. With increasing particle size comes with increasing mass diffusion resistances, thus it is harder for the produced gases to diffuse out from inside the particle. It is also noted that with larger particle size, the smaller is the total surface area available for the gasification to occur, which also contributed on the decreasing syngas production at larger particle size. Moreover, large particles are difficult to be captured by fluidizing gas and Thus, the reactions such as dry reforming of hydrocarbon and methanation take longer time to be achieved.

\section{Effect of air to biomass ratio on syngas composition}

Figure 8 demonstrates how the ratio of air to biomass affects syngas composition in gasification. The oxygen content in the air is approximately $21 \%$. Two trends can be observed in Figure 8 , in

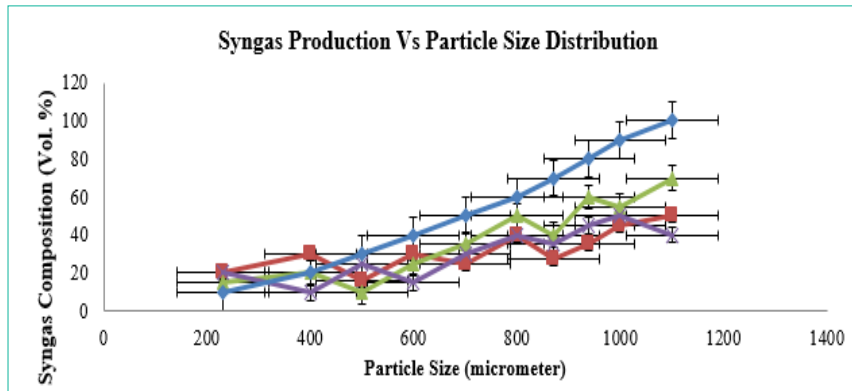

Figure 7: Effect of Particle Size Distribution on Syngas Composition.

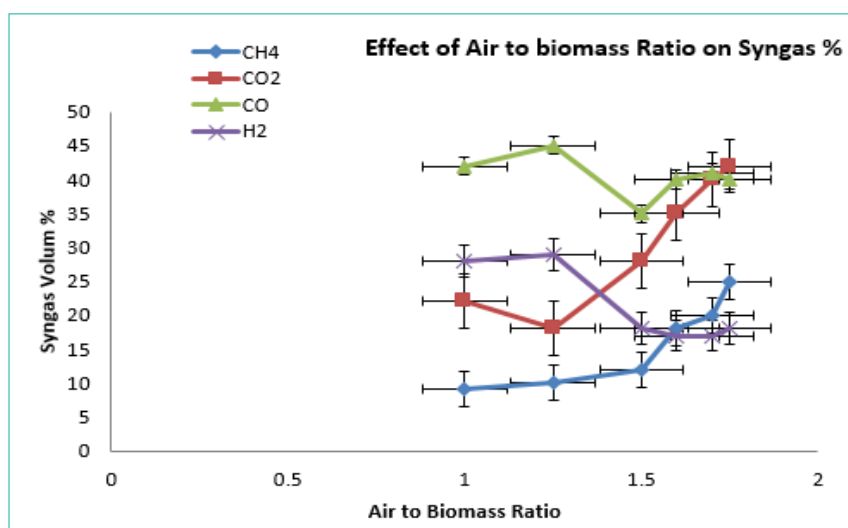

Figure 8: Effect of Air to Biomass Ratio on Syngas Composition.

which $\mathrm{H}_{2}$ and $\mathrm{CO}$ content firstly increased and then followed by decrement as air to biomass ratio increased. Similar trend is reported in previous study when they studied the $\mathrm{H}_{2}$ production performance from air gasification of agriculture waste. The air to biomass ratio is not only portrays the quantity of oxygen inserted to the gasifier but also plays a role in the gasification temperature under auto thermal operation condition. The higher the air to biomass ratio means the higher the gasification temperature, in which the gasification process is accelerated due to increased oxygen content, subsequently enhance the purity of the product to a certain extend. Thus, two opposing factors of air to biomass ratio are both influencing the composition of the gas. The results showed that as the air to biomass ratio increased from 1 to 1.25 , more heat is released to enhance the tar cracking secondary reaction, resulting in increasing $\mathrm{H}_{2}$ and $\mathrm{CO}$. However, excess of air as gasifying agent would promote the oxidation of $\mathrm{CO}$ to $\mathrm{CO}_{2}$. Therefore, the $\mathrm{CO}_{2}$ composition increased associated with a significant dropped in $\mathrm{CO}$ composition. Furthermore, the $\mathrm{CH}_{4}$ had shown significant increasing trend due to intensification of the $\mathrm{CH}_{4}$ combustion; in which large number of gaseous and combustion reactions retards methanation reaction (Figure 9).

\section{Syngas composition obtained using fluidized bed reactor}

One of the most important techniques is the application of dual phase gasifier using steam explosion. The result of steam explosion the biomass burning get started with the increase of steam flow rate the composition of syngas including all its major components will increase. A fluidized bed reactor takes advantage of the excellent mixing characteristics and high reaction rates of gas solid mixtures. A simple fluidized-bed reactor consists of a chamber containing a bed of inert particles such as sand, supported by a distributor plate. 


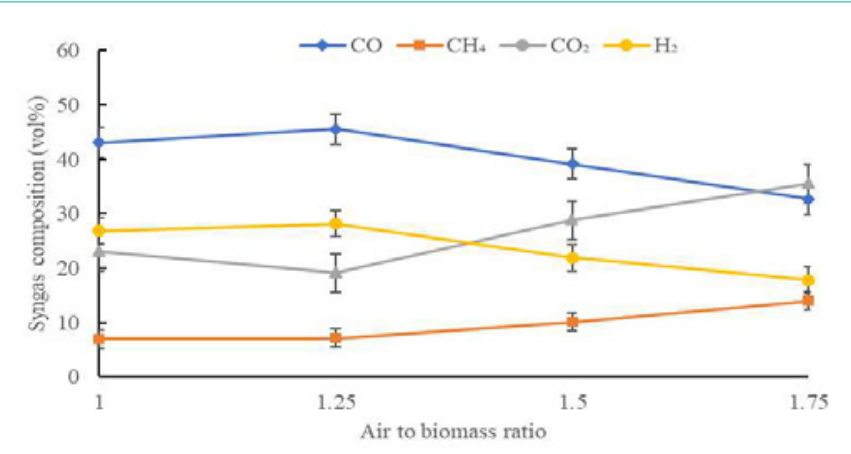

Figure 9: Effect of Air to Biomass Ratio on Syngas Volume [9].

Pressurized air is passed through the distributor plate and the velocity of the air is progressively increased so as to support the entire weight of the bed by the fluid drag on the bed particles due to the upward flowing air. The bed is then said to be incipiently fluiuidized, and it exhibits fluid like properties above this particular velocity, called minimum fluidization velocity. This moving mass of solid particles is called a fluidized bed. The turbulence of the bed increases with velocity, above the minimum fluidization velocity. In energy conversion (for example, combustion or gasification) process, the fluidized bed is first heated externally close to the operating temperature. The bed material, usually sand, absorbs and stores the heat, while the turbulence and mixing of the bed keeps the temperature very uniform throughout the bed. When biomass fuel is introduced into the fluidized bed, the high heat and mass-transfer characteristics of the bed permits the rapid energy conversion at practically isothermal condition. The high surface area available in fluidized beds, and the constantly moving area per unit volume on which reactions can occur, result in good conversion efficiency, higher throughput, and lower operating temperature when compared to fixed beds. Uniform temperatures and high heating capacities of sand media permits a wide range of low-grade fuels of even non-uniform size and varying moisture content to be converted to desired products. Pre-processing of biomass feeds to acceptable particle size and/or moisture content, usually necessary for other conversion technologies, can then be minimized in fluidized-bed.

\section{Conclusion}

In dual fluidized bed the efficiency of reactor was increased from 90-95\%. Similarly at the same time the conversion of the reactor achieved was $92 \%$ as compared to the fixed bed reactor. Under different operating conditions, the whole gasification system runs steadily and shows similar temperature curves along the height of the riser. The highest flaming pyrolysis was in the composition of $100 \%$ rice husk pellets, as where high percentage of $\mathrm{CO}$ and $\mathrm{H}_{2}$ gas on the $\mathrm{RH}$ pellets composition on $700-750^{\circ} \mathrm{C}$. The lowest ash content approximately $30 \%$ occurred in the composition of rice husk pellet than blending mixture and $\mathrm{RH}$ pellets. This shows that the better combustion process can produce the less ash content. The process optimization study of catalytic gasification was successfully conducted in the TGA-MS system with coal bottom ash as catalyst. It was found out that the optimum input parameters for syngas composition were at reaction temperature of $900^{\circ} \mathrm{C}, \mathrm{RH}$ particle size of $250 \mu \mathrm{m}, 10 \mathrm{wt} \%$ of amounts of catalyst and 1.25 air to biomass ratio to obtain 75.8 vol\% of syngas. The optimum conditions of the air gasification obtained in the TGA-MS study was also applied in a fixed bed gasifier to confirm the influences of coal bottom ash as catalyst further. It showed that the syngas composition obtained using fixed bed reactor was 3.25\% higher than TGA-MS (76.2 vol \%). From the PCA analysis, it showed that reaction temperature is the dominant factor in enhancing the syngas composition and catalyst loading is the most insignificant factor in producing the syngas.

\section{References}

1. Zhang Z, Pang S. Experimental investigation of tar formation and producer gas composition in biomass steam gasification in a $100 \mathrm{~kW}$ dual fluidized bed gasifier, Renew. Energy. 2019; 132: 416-424.

2. JH Pauls, Mahinpey N, Mostafavi E. Simulation of air-steam gasification of woody biomass in a bubbling fluidized bed using Aspen Plus: a comprehensive model including pyrolysis, hydrodynamics and tar production. Biomass Bioenergy. 2016; 95: 157-166.

3. D Roy, S Samanta, Ghosh S. Techno-economic and environmental analyses of a biomass based system employing solid oxide fuel cell, externally fired gas turbine and organic Rankine cycle. J. Clean. Prod. 2019; 225: 36-57.

4. Undang-undang UU 30/2007. Tentang Energi dan PP 70/2009 Tentang Konservasi Energi.

5. Li Y, Liu H. "High-pressure densification of wood residues to form an upgraded fuel". Biomass and Bioenergy. 2000; 19: 177-186.

6. Sims R. "Climate change solutions from biomass, Bioenergy and biomaterials". International Commission of Agricultural Engineering. 2003.

7. Wiyono A, Gandidi IM, Berman ET, Pambudi NA. "Design, development and testing of integrated downdraft gasifier and multi IGCS system of MSW for remote areas". Case Stud. Therm. Eng. 2020; 20: 100612.

8. Zheng J, Zhu X, Guo Q, Zhu Q. "Thermal conversion of rice husks and sawdust to liquid fuel". Waste Manag. 2006; 26: 1430-1435.

9. Pathak BS. "Biomass to power rural development". Proc. of National Seminar on Biomass Based Decentralized Power Generation. 2005; 3: 3-6.

10. Jenkins $B$, Mullinger $P$. Industrial and process furnaces: principles, design and operation. Elsevier. 2013.

11. J Werther. "Gaseous emissions from waste combustion". J Hazard Mater. 2007; 144: 604-613.

12. Bach-Oller A, Kirtania K, Furusjo E, Umeki K. "Co-gasification of black liquor and pyrolysis oil at high temperature: Part 1. Fate of alkali elements". Fuel. 2017; 202: 46-55

13. Ding L. "Development of an ultra-small biomass gasification and power generation system: Part 2. Gasification characteristics of carbonized pellets/ briquettes in a pilot-scale updraft fixed bed gasifier". Fuel. 2018; 220: 210219.

14. Y Zhao, S Sun, H Che, Y Guo and C Gao. "Characteristics of cyclone gasification of rice husk". International Journal of Hydrogen Energy. 2012; 37: 16962-16966.

15. JJR Behainne and JD Martinez. "Performance analysis of an air blown pilot fluidized bed gasifier for rice husk". Energy for Sustainable Development. 2014; 18: 75-82.

16. X Gao, F Xu, F Bao, C Tu, Y Zhang, Y Wang, et al. "Simulation and optimization of rice husk gasification using intrinsic reaction rate based CFD model". Renewable Energy. 2019; 139: 611-620.

17. PC Murugan and SJ Sekhar. "Species-Transport CFD model for the gasification of rice husk (Oryza Sativa) using downdraft gasifier. Computers and Electronics in Agriculture. 2017; 139: 33-40.

18. K Manatura, JH Lu, KT Wu and HT Hsu. "Exergy analysis on torrefied rice husk pellet in fluidized bed gasification". Applied Thermal Engineering. 2017; 111: 1016-1024. 
19. PW Olupot, A Candia, E Menya, and R Walozi. "Characterization of rice husk varieties in Uganda for biofuels and their techno economic feasibility in gasification”. Chemical Engineering Research and Design. 2016; 107: 63-72.

20. B Urych and A Smoliński. "Sewage sludge and phytomass co-pyrolysis and the gasification of its chars: A kinetics and reaction mechanism study". Fuel. 2021; 285: 119186

21. DT Pio, LAC Tarelho, AMA Tavares, MAA Matos and V Silva. "Co-gasification of refused derived fuel and biomass in a pilot-scale bubbling fluidized bed reactor". Energy Convers Manag. 2020; 206: 112476.
22. H Shi, N Mahinpey, A Aqsha and R Silbermann. "Characterization, thermochemical conversion studies, and heating value modeling of municipa solid waste". Waste Manag. 2016; 48: 34-47.

23. VCJ Singh and SJ Sekhar. "Performance studies on a downdraft biomass gasifier with blends of coconut shell and rubber seed shell as feedstock". Applied thermal engineering. 2016; 97: 22-27. 